\title{
Devenir inhóspito del hogar: transformaciones territoriales por la presencia de minas antipersonal en Colombia
}

\section{Devir inóspito de casa: transformações territoriais pela presença de minas antipessoal na Colômbia}

\section{Inhospitable home-becoming: territorial transformations caused by antipersonnel landmines in Colombia}

iD

\author{
Gabriel Ruiz Romero \\ Universidad de Medellín, Medellín, Colombia \\ gruiz@udem.edu.co
}

iD

\author{
Daniel Castaño Zapata \\ Universidad de Medellín, Medellín, Colombia \\ dcastano@udem.edu.co
}

Resumen: En este artículo nos preguntamos por la manera en que la presencia de minas antipersonal (MAP) modifica la relación que tienen comunidades rurales con su territorio. Sostenemos que la presencia de MAP produce efectos sociales que dan forma a un devenir siniestro o inhóspito del territorio, es decir, a su transformación en algo que es al tiempo familiar y extraño. Este fenómeno sustenta las dinámicas de dominación por parte de los grupos armados responsables de la instalación de aquellos artefactos. El artículo es producto del trabajo de memoria histórica realizado en tres municipios colombianos con miembros de asociaciones de víctimas de MAP. El texto concluye que la instalación de estas armas, en tanto estrategia de los grupos armados para continuar la guerra bajo tierra, no sólo afecta a los individuos que 
caen en dichas trampas explosivas, sino que altera profundamente el sentido social de hogar que un territorio específico tiene para una comunidad local.

Palabras clave: Minas antipersonal. Conflicto armado. Colombia. Territorio. Siniestro.

Resumo: Este artigo pergunta como a presença de minas antipessoal (MAP) muda a relação das comunidades rurais com seu território. Sustentamos que a presença das MAP produz efeitos sociais que conformam um devir sinistro ou inóspito do território, isto é, sua transformação em algo ao mesmo tempo familiar e estranho. Esse fenômeno sustenta as dinâmicas de dominação por parte dos grupos armados responsáveis pela instalação daqueles artefatos. Este artigo apresenta o trabalho de memória histórica realizado em três municípios colombianos com membros de associações de vítimas de MAP. O texto conclui que a instalação dessas armas, como estratégia dos grupos armados para dar continuidade à guerra subterrânea, não afeta só as pessoas vitimadas por tais armadilhas explosivas, mas muda profundamente o sentido social de casa que determinado território configura para uma comunidade local.

Palavras-chave: Minas antipessoal. Conflito armado. Colômbia. Território. Sinistro.

Abstract: This article asks how the presence of antipersonnel mines (APMs) changes the relationship between rural communities and their territory. We argue that the presence of APMs produces social effects that shape a sinister or inhospitable territory-becoming, i.e. its transformation into something that is both familiar and uncanny. This phenomenon supports the domination dynamics on the part of armed groups responsible for the installation of those artifacts. This article introduces the historical memory study carried out in three Colombian municipalities with members of associations of victims of APMs. The text concludes that the installation of these weapons, as a strategy of the armed groups to continue the underground war, does not only affect 
people victimized by such explosive traps, but profoundly changes the social sense of home that a given territory has for a local community.

Keywords: Antipersonnel mines. Armed conflict. Colombia. Territory. Incident.

Data de recebimento: 29/04/2020

Data de aprovação: 18/09/2020

El espacio geográfico es, en esencia, un espacio existencial. Y, en este espacio, los lugares no son simples localizaciones; no son sólo el cruce de un eje de coordenadas conformado por paralelos y meridianos. Son mucho más que eso: son porciones del territorio imbuidas de significados, de emociones $y$, por lo tanto, llenas de significados para los seres humanos.

(NOGUÉ, 2014, p. 157). 
Devenir inhóspito del hogar: transformaciones territoriales por la presencia de minas...

\section{Introducción}

Laguerraen Colombiahatenidolugarenespaciossuperpuestos: los lugares donde gran parte de la población -en su mayoría campesina- ha buscado construir su proyecto de vida y mantener allí unas dinámicas cotidianas de apropiación y vertimiento de sentido sobre el territorio son los mismos que en lógica bélica han sido considerados zonas o corredores estratégicos en disputa. El problema de esta doble apropiación del territorio (desde la vida cotidiana de poblaciones civiles y desde la estrategia militar de los diferentes actores, legales e ilegales, que combaten en el país) es que la segunda dificulta enormemente la primera, cuando no la anula por completo. Lo anterior debido a que aquellos que han sostenido y prolongado el conflicto armado colombiano "imponen forzosamente su lógica bélica sobre las prácticas de construcción territorial de las poblaciones" (CNMH, 2017, p. 127).

El empleo de minas antipersonal (MAP) ha sido uno de los repertorios mediante los cuales ha tenido lugar esta re-significación violenta del territorio. El hecho de que los efectos victimizantes de estas armas tengan un carácter diacrónico, esto es, que su poder destructivo se mantenga activo años después de haber sido instaladas, hace que la afectación territorial que ellas representan se conserve incluso después de que un conflicto armado ha cesado. Es por esto que el uso de MAP como táctica de guerra es bastante disruptivo para la población civil, pues introduce una indefinida incertidumbre -tanto en términos espaciales como temporalesen el espacio donde transcurre la vida cotidiana.

Si la instalación de MAP en un territorio ha sido conceptualizada como una "contaminación" (GICHD, 2014) es porque infecta un área con elementos extraños que destruyen su composición tradicional, transfigurando así los usos y percepciones que una población tiene respecto del lugar que habita (GMH, 2009). El sentido del espacio social, construido a través de relaciones prolongadas de una comunidad con el espacio físico que habita y de las propias 
Devenir inhóspito del hogar: transformaciones territoriales por la presencia de minas... Gabriel Ruiz Romero • Daniel Castaño Zapata

relaciones que los miembros de esa comunidad han tejido entre sí en ese lugar específico, se ve fuertemente afectado cuando lo que antes era conocido y familiar se torna amenazante. Así, al tener la capacidad de añadir lo hostil a lo familiar, el uso de MAP o la presencia de remanentes explosivos de guerra (REG) tornan siniestro el territorio'.

La idea de lo siniestro ha sido objeto habitual de estudios literarios y psicológicos. Schelling (2006) afirma que lo siniestro es lo que produce una "extrañeza inquietante" en el acto de manifestarse. Es en esta línea que Freud (1968) explora el concepto y lo define como esa perturbadora sensación de extrañeza y temor generada por lo que otrora fuese familiar o incluso amado. No es entonces la extrañeza de lo otro sino de lo propio lo que configura lo siniestro. Es esta última idea, llevada al proceso de transformación de la relación que establece una comunidad con el territorio que habita debido a la contaminación por MAP y REG, lo que rastreamos en este artículo, optando por una de las variaciones del término: lo inhóspito. Consideramos que esa mutación hacia lo inhóspito es un elemento fundamental de los procesos de dominación y control social por parte de los actores armados ilegales del conflicto armado colombiano.

El trabajo de recolección y construcción de información primaria que sustenta nuestro análisis se desarrolló en el oriente antioqueño, región aledaña a la ciudad de Medellín. El departamento de Antioquia encabeza la lista de victimización a nivel nacional. En un país que tiene registradas 11.801 víctimas directas de MAP y REG, este departamento concentra el 9,8\% de todas las víctimas (AICMA, 2020a)2. La afectación en este departamento ha estado condensada particularmente en 3 zonas: a) el norte; b) el nordeste; y c) el oriente. El trabajo de campo fue realizado específicamente

\footnotetext{
1 Los REG son "las municiones abandonadas o municiones usadas sin explosionar" (CENAM, 2020) que pueden ser granadas, morteros, balas, municiones de fabricación improvisada, entre otros. En la base de datos de la Agencia de Acción Integral contra Minas Antipersonal (AICMA) se emplea el término Munición sin Explotar (MUSE) para designar estos mismos artefactos.

2 Aunque existen noticias del empleo de MAP desde la década de 1970, el registro oficial de victimización por estos artefactos (junto con los de REG) se lleva en Colombia solo desde 1990. Ese registro, realizado por la Agencia de Acción Integral contra Minas Antipersonal (AICMA), muestra que de los 1.122 municipios que tiene el país, en 512 se han presentado víctimas de MAP y REG. Esos municipios están distribuidos en 32 de los 33 departamentos que tiene Colombia, con la única excepción de la isla de San Andrés y Providencia. Todas las cifras de victimización por MAP y REG presentadas en este artículo son con corte al 31 de diciembre de 2019.
} 
Devenir inhóspito del hogar: transformaciones territoriales por la presencia de minas... Gabriel Ruiz Romero • Daniel Castaño Zapata

en 3 municipios de esta última zona: a) Cocorná; b) San Francisco; y c) San Luis. Estos 3 municipios tienen registradas 256 víctimas, es decir, el 22\% del total de las víctimas de Antioquia.

Estos tres municipios conforman la denominada zona de Bosques del Oriente Antioqueño. Ubicada a escasos $80 \mathrm{~km}$ de Medellín, se trata de una región que ha tenido presencia guerrillera desde la década de 1970, especialmente la del Ejército de Liberación Nacional (ELN), a través del frente de guerra denominado Carlos Alirio Buitrago. La región también tuvo presencia de las Fuerzas Armadas Revolucionarias de Colombia (FARC), organización que, a través de sus frentes 9 y 47, le disputó el dominio al ELN desde mediados de los años 1980. En la década siguiente haría su entrada violenta las Autodefensas Campesinas de Córdoba y Urabá (ACCU), facción paramilitar de ultraderecha que empleó las masacres indiscriminadas como forma central de su accionar en la guerra colombiana. La zona también fue escenario de grandes operativos militares: entre los años 2003 y 2006, el Ejército colombiano lanzó allí al menos 5 grandes ofensivas contra el ELN y las FARC (SANDOVAL et al., 2017). El hecho de ser zona de disputa entre distintos actores armados hizo que el empleo de MAP aumentara allí, ya que estas armas han sido empleadas en Colombia especialmente por las fuerzas guerrilleras como estrategia defensiva en momentos de operativos militares del ejército o de las organizaciones paramilitares (CNMH, 2017).

El trabajo de campo se diseñó y desarrolló a partir de la realización de 9 talleres de reconstrucción de memoria histórica (3 en cada municipio) sobre la victimización por MAP. En ellos participaron 78 personas miembros de 3 asociaciones de víctimas directas e indirectas (familiares de las primeras) de MAP y REG ${ }^{3}$. A una cuarta parte de los participantes en los talleres le hicimos entrevistas semi-estructuradas. Los talleres de reconstrucción de memoria histórica que se referenciarán a lo largo del texto

\footnotetext{
3 Las asociaciones con las que trabajamos son: Asociación Municipal de Sobrevivientes Civiles de Minas Antipersonal y Munición sin Explotar de Cocorná (ASOMACC); la Asociación de Víctimas de Minas Antipersonal de San Francisco (ASOSAN); y la Asociación de Víctimas de Minas de San Luis (AVIMAS). A todas las integrantes de estas organizaciones damos nuestro agradecimiento por posibilitarnos realizar el trabajo y les expresamos nuestra admiración por la forma en que asociativamente han afrontado su situación.
} 
Devenir inhóspito del hogar: transformaciones territoriales por la presencia de minas... Gabriel Ruiz Romero • Daniel Castaño Zapata

fueron realizados en los años 2015 y 2016, mientras visitas complementarias a campo y entrevistas personales se realizaron en el año 2017. Ha sido el enfoque de etnografía conmutante (WERNER y SHOEPFLE, 1993) y de etnografía multilocal (MARCUS, 1995) el que ha guiado la investigación. En ellos, el investigador sigue la trama y los personajes que constituyen su objeto de estudio, mediante entradas y salidas de campo regulares durante un periodo de tiempo.

\section{Breve contexto y dinámica regional del conflicto armado}

La subregión del oriente antioqueño aparece oficialmente a partir de los procesos de subregionalización administrativa del departamento de Antioquia, llevados a cabo en el año 1975. Estos se dieron a raíz de estudios y análisis realizados por el Departamento Administrativo de Planeación, que delimitó unas áreas homogéneas a partir de la consideración de variables relacionadas con aspectos ambientales, físico-espaciales, económicos, culturales y sociales. El oriente antiqueño fue, así, una de las 9 subregiones en que quedó administrativamente distribuido el departamento (GÓMEZ, HINESTROZA e MUÑETÓN, 2008).

La agricultura a pequeña escala y los cultivos de pancoger (como yuca, maíz, fríjol, plátano, caña de azúcar, cacao) han tenido una presencia tradicional en la zona. La explotación forestal ha ocupado también un importante papel en la economía de las familias, al igual que la extracción de mármoles y piedra caliza. A partir de los años 1960, la dinámica social y económica de la región se vio alterada de forma acelerada por la construcción de grandes proyectos de desarrollo en la zona. Primero fue la construcción de la autopista que une Medellín (capital del Departamento de Antioquia) y Bogotá. Posteriormente, la construcción de embalses e hidroeléctricas en el territorio y del aeropuerto internacional que brinda servicios aeroportuarios a la ciudad de Medellín. En 
Devenir inhóspito del hogar: transformaciones territoriales por la presencia de minas...

un periodo de 2 décadas, se pasó "de la agricultura campesina a los megaproyectos" (PNUD, 2010, p. 5), lo que produjo cambios en la composición demográfica y dio además inicio a luchas sociales, especialmente alrededor del desplazamiento poblacional que supuso la construcción de los embalses y las hidroeléctricas (URIBE, 2001).

Precisamente el ELN utilizó instrumentalmente estas luchas sociales para entrar en la región. A partir de la década de 1980, este grupo guerrillero hizo su ingreso en la zona, haciendo propias las reivindicaciones locales frente a los profundos cambios sociales y en la estructura económica que estaban teniendo lugar allí, buscando así adquirir legitimidad en la región. Se trata de una estrategia que esta organización armada ha empleado en diversos lugares del país, buscando a través de ella ganar apoyo político mediante el trabajo de difusión de sus planteamientos políticos en el contexto de las luchas sociales de las regiones donde busca hacerse un espacio y crear base social (PEÑATE, 1999; AGUILERA, 2006).

Primero las FARC y después los paramilitares de extrema derecha de las ACCU entrarían a la región a disputarle ese dominio al ELN. Estos últimos llegaron desde la fronteriza región del Magdalena Medio, donde ejercían pleno dominio territorial. Su autodenominada lucha contrainsurgente se dio, en la práctica, a través de acciones contra la población civil: masacres y asesinatos selectivos que produjeron desplazamientos forzados colectivos en varios municipios de la región (OBSERVATORIO DEL PROGRAMA PRESIDENCIAL DE DERECHOS HUMANOS Y DERECHO INTERNACIONAL HUMANITARIO, 2003; CNMH, 2013). Lo de las FARC, por su parte, constituyó una "colonización guerrillera a punta de bala" (VERDAD ABIERTA, 2014), en la que los secuestros, la toma armada de poblaciones y los asesinatos selectivos representaron la forma de hacer su entrada y consolidación en la región.

Las diferencias en el modus operandi para ingresar y ejercer dominio en la región se perciben incluso en la forma en que los pobladores locales recuentan la presencia de los distintos grupos. 
Devenir inhóspito del hogar: transformaciones territoriales por la presencia de minas... Gabriel Ruiz Romero • Daniel Castaño Zapata

Al preguntarle por la forma cómo fue sintiéndose la presencia de los grupos armados en el territorio, un campesino de San Francisco recordaba:

En el año de 1985 llegó el noveno frente de las FARC y ellos tenían dominada parte del municipio de San Carlos y toda la parte de Sonsón, Argelia y Nariño. En el año de 1990 llegaron tres personas, dos hombres y una mujer. Eran del ELN y se Ilamaban Elenos. Las FARC imponían más miedo, casi nunca se dejaban ver y era gente acuerpada y con cara de no ser de estos lados y se mantenían muy armaos. Los Elenos llegaron tres y se fueron ganando la confianza de la gente; incluso en ese entonces andaban sin uniforme $y$ prácticamente sin armas. (Hombre adulto, entrevista personal, San Francisco, 26 nov. 2016)

Para el tema, nos interesa señalar que la disputa armada por el dominio de una región centro de megaproyectos y con la posibilidad de controlar la principal vía terrestre del país conllevó a la agudización del conflicto armado allí y al empleo creciente de MAP como arma de guerra central en esta disputa. En efecto, en el oriente antioqueño, las MAP aparecieron como estrategia de repliegue de la guerrilla. Entre 1997 y 1999, tuvieron lugar constantes bloqueos y retenes del ELN y de las FARC en diferentes puntos de la autopista Medellín-Bogotá. En medio de estas operaciones guerrilleras, la quema de vehículos que quedaban atravesados en la vía y los atentados contra la infraestructura vial y energética empezaron a ser habituales. Es justo esto lo que recuerda una mujer de San Luis cuando hace memoria de los días más álgidos de la guerra en su municipio:

Cuando tumbaron el puente de Samaná yo estaba de dieta de mi hija. Tumbaron el puente y la gente cayó rio abajo. El puente se demoró mucho para hacerlo, en la noche la gente no sabía y caía al rio. (Mujer adulta, taller de memoria, San Luis, 12 ago. 2015) 
Devenir inhóspito del hogar: transformaciones territoriales por la presencia de minas... Gabriel Ruiz Romero • Daniel Castaño Zapata

Las acciones en la autopista les posibilitaban a estos grupos realizar secuestros extorsivos que alimentaban sus finanzas. Adicionalmente, estar posicionados así en el terreno (controlando la principal arteria vial de la región) les facilitaba las incursiones violentas de los pueblos cercanos a la autopista4. Después de ejecutar este tipo de acciones, tanto el bloqueo de la autopista como las tomas de los pueblos, los grupos guerrilleros minaban el territorio circundante a la vía o a los municipios para proteger su retiro: "después que la guerrilla salía [del pueblo después de una incursión] dejaba minas antipersonal" y estos artefactos explosivos quedaban escondidos "en algún lugar del monte o de los bosques" (Hombre adulto, taller de memoria, San Luis, 12 ago. 2015). Fue esta misma estrategia (minar la retaguardia) la que fue empleada cuando la guerrilla tuvo que replegarse a la zona de páramos del oriente antioqueño debido a las presiones militares que afrontaron, tanto por parte del Ejército Colombiano como por parte de los paramilitares de las ACCU.

En total, han sido 519 personas registradas como víctimas directas por MAP en el oriente antioqueño (AICMA, 2020a)5. De ellas, 347 han sido civiles. Los participantes en los talleres de reconstrucción de memoria histórica recordaron que hasta mitad de la década de 1990 no habían escuchado hablar de MAP. De hecho, la primera víctima reportada para el oriente antioqueño en la base de datos de la Agencia de Acción Integral contra Minas Antipersonal (AICMA) aparece en 1995 (Gráfico 1). Se trató de una víctima militar por un hecho producido en el municipio de Cocorná. Dos años después sucedió la victimización por MAP de la primera víctima civil en la región.

\footnotetext{
4 Los tres municipios donde realizamos el trabajo de campo fueron objeto de tomas o incursiones armadas por parte de las dos organizaciones guerrilleras. Como resultado de dichas incursiones, parte de los pueblos fue destruida debido a la detonación de explosivos por parte de la guerrilla en su ataque a las instalaciones de la fuerza pública o de las cajas agrarias locales.

5 Es preciso señalar que la afectación por MAP no sólo genera víctimas directas, sino también víctimas indirectas, las cuales no están reflejadas en las cifras. Debido a la afectación que esta forma de victimización crea en el núcleo familiar y a los arreglos de género presentes en la zona, podemos afirmar entonces que son muchas más las mujeres que han visto afectadas sus vidas debido a estos artefactos explosivos (al respecto ver VALENCIA y RUIZ, 2016).
} 
Devenir inhóspito del hogar: transformaciones territoriales por la presencia de minas...

Gráfico 1. Víctimas por MAP y REG en el oriente antioqueño 1995-2017.

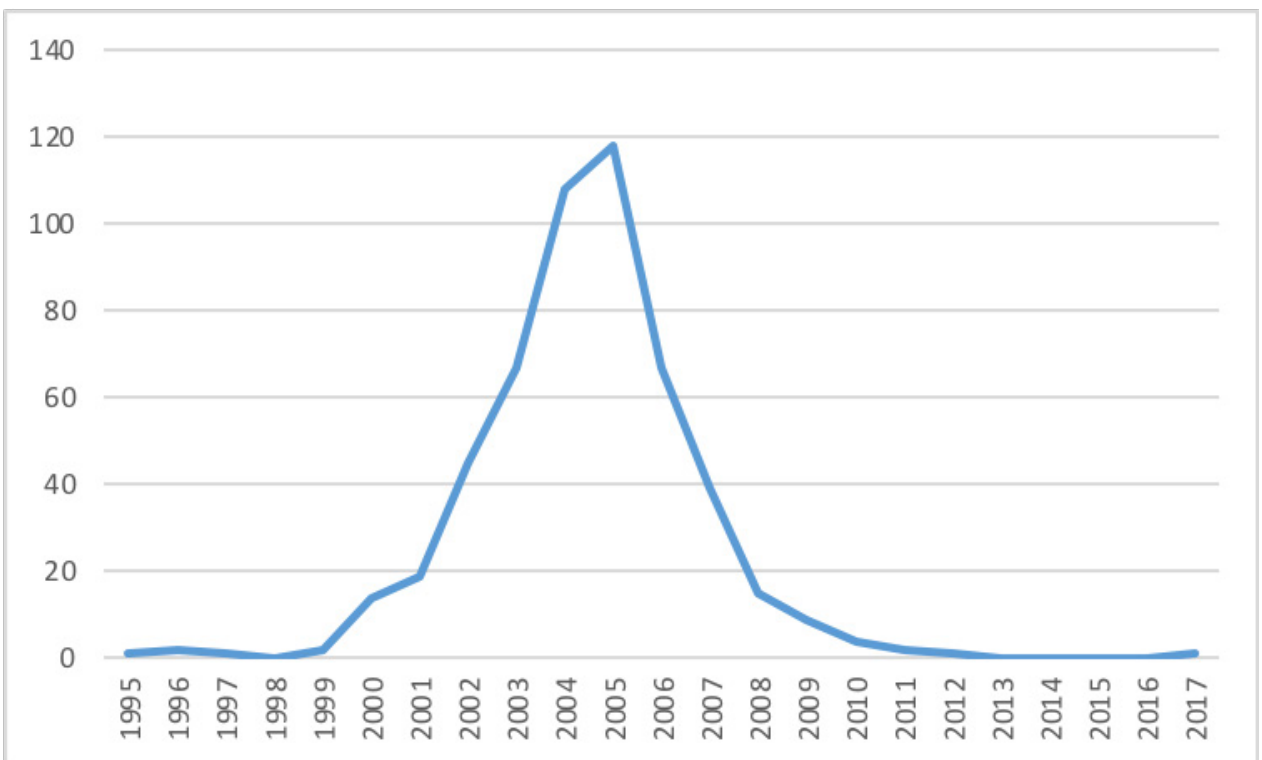

Fuente: Adaptado de AICMA (2020a).

A partir del año 2000, la afectación por MAP y REG empieza a crecer en la región del oriente antioqueño, llegando a su punto más alto en el año 2005. Este periodo de agudización coincide con la etapa en la que las Fuerzas Militares retomaron la iniciativa en la región, mediante el desarrollo de los operativos militares indicados en la introducción. El Gráfico 2 muestra los combates que tuvieron lugar entre la Fuerza Pública y los grupos guerrilleros por iniciativa de la primera (es decir, en el contexto de operativos militares) y las acciones de guerra de la guerrilla en el oriente antioqueño. Si comparamos el Gráfico 1 y el Gráfico 2, se confirma que el periodo de mayor victimización por MAP y REG coincide con el de los operativos militares de la Fuerza Pública. 
Devenir inhóspito del hogar: transformaciones territoriales por la presencia de minas... Gabriel Ruiz Romero • Daniel Castaño Zapata

Gráfico 2. Combates por iniciativa de la Fuerza Pública versus las acciones por iniciativa de las guerrillas entre 1986 y 2012.

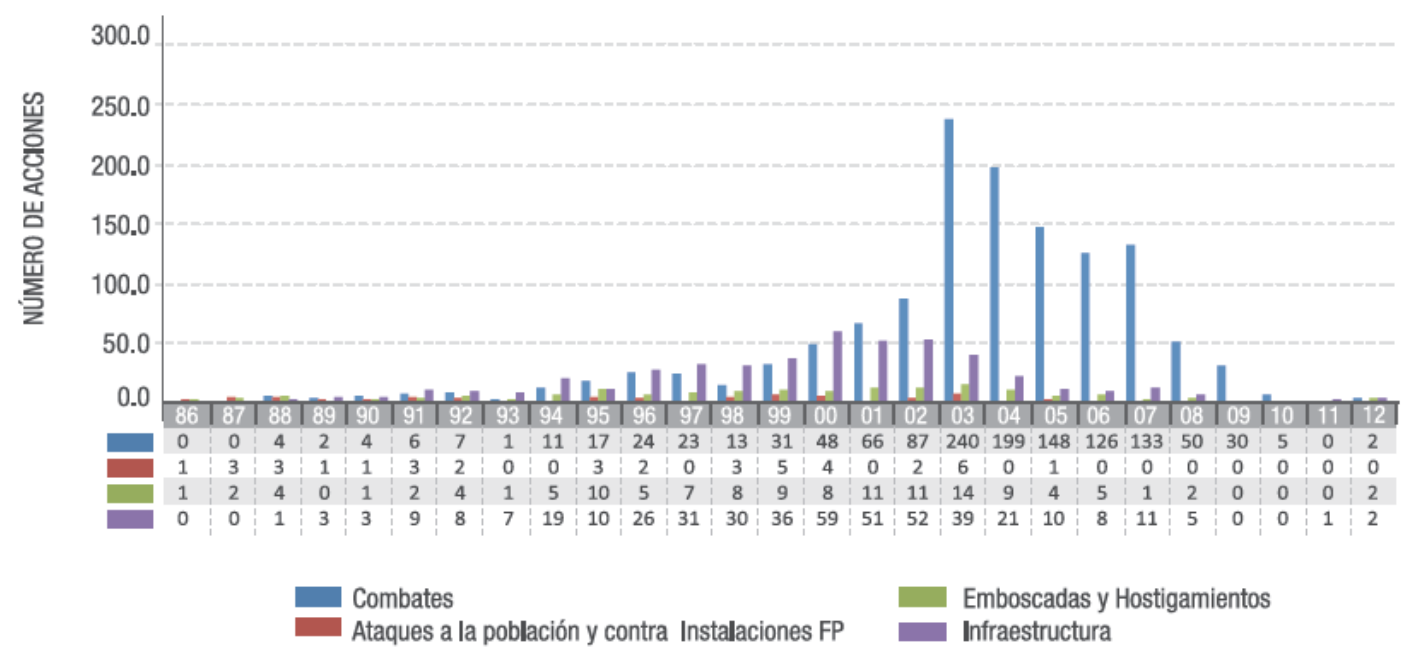

Fuente: Observatorio de la Consejería de Presidencia para los Derechos Humanos (2015, p. 455).

El progreso del aumento de las cifras de víctimas de MAP coincide entonces con la ofensiva de la fuerza pública en la región y con la entrada y el posicionamiento de los paramilitares allí mismo. Estas presiones militares obligaron a los dos frentes de las FARC que operaban en el área (el $9^{\circ}$ y el 47 ) a replegarse en zonas montañosas y boscosas. Estos repliegues estuvieron acompañados por la instalación de MAP en los lugares susceptibles de ser atravesados por sus enemigos, brindando tiempo y distancia para evitar contactos o enfrentamientos directos. Esos artefactos solían ser instalados en lugares estratégicos que la guerrilla anticipaba podían ser atravesados por la tropa del Estado o de los paramilitares en sus desplazamientos: nacimientos y fuentes de agua, zonas de sombra, ramas de los árboles de ciertos caminos o camuflados entre objetos que puedan ser empleados cotidianamente, como trozos de leña (CNMH, 2017).

Pero como se hace evidente sólo al enunciar los lugares donde potencialmente la guerrilla instala estos artefactos, esos lugares son también por los que suele transitar la población civil que habita el territorio. El reporte nacional de memoria sobre MAP 
Devenir inhóspito del hogar: transformaciones territoriales por la presencia de minas... Gabriel Ruiz Romero • Daniel Castaño Zapata

en Colombia (CNMH, 2017) señala que una de las características principales de esta arma de guerra es el carácter indiscriminado de la victimización que produce. En efecto, las víctimas de MAP y REG en el territorio objeto de estudio no fueron solo militares, sino también civiles campesinos que activaron una de estas armas cuando se desplazaban por su territorio. Mientras que para los actores en conflicto un territorio determinado es un escenario de una guerra más amplia, y el mismo puede "ganarse" o "perderse" y migrar hacia otros frentes, para la población ese territorio es su hogar; lo han construido y habitado como paisaje propio y la presencia de objetos extraños y peligrosos amenaza justamente dicha construcción social del paisaje.

\section{Lo desconocido se revela}

Dice Scheler (2017) que, para poder encontrar nuestro lugar en el mundo, ese mundo debe ser un cosmos (un mundo ordenado), pues en el caos no es posible identificar ningún lugar. Un lugar en el mundo, un hogar, es un lugar de protección para quien está vinculado a él (RELPH, 1976, p. 38). Así, llamamos hogar al espacio que organizamos a nuestro alrededor para sentirnos resguardados, protegidos. Es por esto que más que un lugar geográfico, el territorio es un proceso antropológico: un paisaje se hace territorio cuando se humaniza por la acción de comunidades que dejan su huella en él y lo hacen su hogar. El hombre construye territorio, construye su territorio, en la medida en que vierte un sentido en él para transformarlo paulatinamente en su lugar en el mundo. Es, en esencia, ese sentido el primero que sufre una transformación cuando actores armados empiezan a hacer de ese mismo territorio su escenario de confrontación.

La presencia de MAP o de REG es precisamente una forma poderosa de transfigurar un paisaje habitual, haciéndolo hasta cierto punto hostil. La violencia tiene el poder de transformar con 
Devenir inhóspito del hogar: transformaciones territoriales por la presencia de minas... Gabriel Ruiz Romero • Daniel Castaño Zapata

un solo acto el sentido de un espacio que había sido construido a través del tiempo por una comunidad $(\mathrm{GMH}, 2009)$. La instalación de estos artefactos en un territorio, en tanto estrategia de los grupos armados de "continuación de la guerra bajo tierra" (OBSERVATORIO DE MINAS ANTIPERSONAL, DEFENSORÍA DEL PUEBLO y UNICEF, 2005, p. 11), altera su sentido porque logra -de forma simbólica y literal- transformar el entorno en el cual se desenvuelve la vida comunitaria. Su poder devastador es profundo, pues las MAP se apropian de los terrenos productivos y de los espacios sociales de una comunidad, incluso después de un eventual cese de hostilidades bélicas.

En efecto, la instalación de MAP tiene especialmente un efecto diacrónico, porque el poder destructivo de estas armas se mantiene activo por años (incluso por décadas, en el caso de las MAP industriales), y por ello pueden seguir presentándose activaciones de las mismas mucho tiempo después de haber sido instaladas, aunque el conflicto haya cesado en un territorio o su intensidad allí haya disminuido. Las MAP pueden esperar agazapadas mucho tiempo, mimetizadas en el paisaje, hasta que alguien las detone. Es por ello que han sido llamadas el "león dormido" que despierta al ser activadas por sus víctimas ( $\mathrm{CNMH}, 2017$, p. 37). Un enemigo que parece dormir pero que en realidad se mantiene activo en potencia a través de un espacio prolongado de tiempo.

Dijimos que un paisaje se humaniza al hacerse territorio. Una comunidad construye territorio no sólo a partir de las transformaciones físicas que ejecuta sobre él (arar los campos, trazar caminos, sembrar o talar bosques, etc.), sino porque esa comunidad le da un sentido particular a ese paisaje que ha devenido territorio: su hogar, el lugar de sustento, espacio de esparcimiento, etc. $Y$ es ese sentido el que alternan las acciones armadas:

(...) que [los miembros de un grupo armado] necesitaban yo no sé cuántos metros de tierra, que ellos necesitaban el espacio, pues según dijeron, ellos lo necesitaban porque se iban a enfrentar con otro grupo. (Mujer adulta, entrevista personal, Cocorná, 15 jul. 2017) 
Devenir inhóspito del hogar: transformaciones territoriales por la presencia de minas... Gabriel Ruiz Romero • Daniel Castaño Zapata

Esos ejércitos reclamando no sé cuántos metros de tierra, apropiándose del territorio para convertirlo en un espacio de confrontación, alteran el sentido de dicho territorio al introducir nuevas dinámicas hasta entonces ajenas en la vida de la comunidad.

El uso de MAP es central en esta transformación bélica de las dinámicas territoriales locales. Los espacios no pueden ya ser habitados ni transitados como antes. Incluso en las cabeceras municipales empiezan a aparecer nuevas delimitaciones que marcan los lugares donde ya no es posible estar; lugares apropiados así para la guerra y sustraídos, por tanto, de la vida cotidiana:

(...) porque ahí había minas [en 1998]. Supuestamente había minas; había una calavera [un letrero de advertencia de la presencia de Minas Antipersonal, con una calavera dibujada] y todo eso. Entonces uno no se podía meter. Pero uno a veces se pone a pensar... yo pues personalmente nunca me di cuenta para qué minaron eso ahí. Ahí había un altico, un montecito, puede haber sido que era para vigilar el pueblo desde ahí o no sé. Ahí decía que "campo minado". (Hombre adulto, entrevista personal, San Francisco, 23 jul. 2017)

La imagen de la calavera opera en tanto signo de la transformación física y simbólica del lugar. Incluso en la actualidad, veinte años después de esto y habiéndose declarado de forma oficial a San Francisco como un pueblo "libre de sospecha de minas antipersonal", el lugar donde estuvo ese aviso sigue conociéndose allí como campo minado. No hay ya MAP pero lo que ellas marcaron sigue de alguna forma estando presente. La forma en que estos artefactos movilizan el sentido del territorio es incluso más fuerte en las zonas rurales. No es sólo que la mayoría de víctimas de estas armas en el país se han producido en áreas rurales (el 98\%, según datos del AICMA, 2020a), sino que en estas zonas no suele haber letreros que avisen de su presencia, sino que están camufladas en el paisaje y es el estallido de alguna lo que evidencia que la tierra esconde trampas transformadoras del territorio: 
Devenir inhóspito del hogar: transformaciones territoriales por la presencia de minas... Gabriel Ruiz Romero • Daniel Castaño Zapata

El artefacto (...) estaba enterrado en el piso y en la zona había maleza de un metro con cincuenta centímetros. (Víctima directa de MAP, taller de memoria, Cocorná, 10 sep. 2015)

Señalamos antes que el registro de la primera víctima civil en la región data de 1997. El hombre campesino que sufrió este ataque participó en los talleres que sustentan este texto. Su testimonio da cuenta de algo central en la discusión que proponemos aquí: la aparición de un elemento hasta entonces desconocido en el territorio.

\begin{abstract}
(...) eso [la activación de la MAP] fue en el 97 y no había señas de nada, ni nadie decía nada. Únicamente dijeron que eso era una mina cuando estaba ya en [el hospital] San Vicente. Una mina quiebrapatas, me dijeron unas personas que venían de Urabá, pero por aquí no había nada, ni mencionado que hubiera algo por acá. Ese fue el primer accidente por acá. (Hombre adulto, entrevista personal, San Luis, 26 nov. 2015)
\end{abstract}

Lo desconocido, que permanecía hasta entonces escondido, hace así su aparición violenta. El lugar de protección se altera con el nuevo peligro que representan los actores armados y sus acciones en el territorio, un nuevo peligro que en las narrativas locales trata de ser comparado con los ya existentes para poderle dar algún sentido: "mi papá me decía que me fuera rapidito porque había animales que pican" (Mujer joven, entrevista personal, San Luis, 15 jun. 2017). Se refería así, con esta expresión, a los actores armados que estaban merodeando su territorio, realizando diversas acciones, entre las que se contaba la instalación de MAP.

Expresamos antes que la presencia de estas más hacía hostil el territorio. Aclaramos, sin embargo, que ello sucedía "hasta

6 Urabá es una región al noroccidente del departamento de Antioquia. Las dinámicas de la guerra colombiana hicieron que en
esa región las MAP fueran empleadas años antes de registrarse su empleo en la zona del oriente antioqueño. Por otra parte,
aunque "accidente" es el término oficial con el que el AICMA se refiere al acto de activación de una MAP por parte de su vícti-
ma, y es también ese el término que emplea la propia población, preferimos aquí seguir al CNMH (2017) y hablar de ataques
en lugar de accidentes, para no invisibilizar así al perpetrador que parece desaparecer cuando se habla de un acto accidental. 
Devenir inhóspito del hogar: transformaciones territoriales por la presencia de minas...

cierto punto", ya que el territorio no perdía completamente cierta familiaridad, sino que precisamente empezaba a convertirse en algo al tiempo familiar y extraño o, como diría Trías (1984), es al tiempo acostumbrado y extraño.

El territorio donde empiezan a merodear estos nuevos animales que pican ve alterado así su significado simbólico de lugar de protección. La apropiación social de un territorio tiene lugar a partir de lo que éste genera, a partir de la lectura que del mismo hacen quienes lo habitan. Ayer hogar, lugar de trabajo y de vida social, hoy espacio de peligro donde se esconden nuevos enemigos. Ese doble sentido refleja las contradicciones sociales en la apropiación de un territorio (SEGUINOT, 1996). Por una parte, una comunidad que a través del trabajo de varias generaciones se ha apropiado de ese territorio boscoso como el lugar donde ha hallado su sustento y donde ha construido su hogar; y por el otro, unos grupos que desafían esa apropiación y construcción de sentido comunitario, siguiendo sus lógicas bélicas. Un mismo paisaje, un mismo territorio, dos formas contradictorias de apropiarlo.

La Fundación Seguridad \& Democracia (2006) ha señalado que los grupos armados emplean las MAP para confinar y controlar a una población, pues ésta, avisada de los lugares donde hay minas, tienen que moverse por espacios vigilados. Aunque no ha sido éste el objetivo principal del empleo de minas por parte de la guerrilla en Colombia, el cual ha estado más relacionado con estrategias militares defensivas, como lo señala el informe del CNMH (2017), igualmente el territorio así apropiado se convierte en un espacio de riesgo por la presencia de los artefactos explosivos y frente al accionar y la vigilancia de los grupos armados que mantienen confinada a la población. Así, uno de sus efectos ha sido el de crear temor hacia los caminos por los que transcurre la vida comunitaria local. Uno de los habitantes de San Luis, familiar de una víctima de MAP, lo manifestaba de forma explícita cuando le preguntamos por sus cambios de hábitos en el territorio debido a la presencia de esos artefactos: "a mí no me gusta alejarme de donde la gente camina porque no sabe uno" (Mujer joven, entrevista personal, San 
Devenir inhóspito del hogar: transformaciones territoriales por la presencia de minas... Gabriel Ruiz Romero • Daniel Castaño Zapata

Luis, 15 jun. 2017). Si no se aleja de donde otros ya han caminado, no hay forma entonces de explorar y expandir el territorio. Por este camino, la apropiación social del territorio se detiene.

\section{Devenir inhóspito del territorio}

Hablando sobre la presencia de MAP y REG en su territorio, una mujer adulta de San Francisco (entrevista personal, San Francisco, 26 nov. 2016) recordaba los días a finales de los 1990 y los primeros años del nuevo siglo, diciendo: "me daba temor salir por la sicosis que algo iba a explotar. Prefería permanecer en la finca por miedo a una mina antipersonal" (Mujer, entrevista personal, San Francisco, 26 nov. 2016). Así, en los territorios donde han sido instaladas MAP, el miedo y la incertidumbre se vuelven sensaciones asociadas al hecho de recorrer y habitar dichos territorios. Se teme a un lugar que hasta poco antes se percibía como seguro y previsible.

Las MAP le dan cuerpo a un miedo cuyo sustento es difícil de desacreditar, pues la MAP se transforma en una potencialidad actualizable en cualquier momento. Por un lado, el carácter diacrónico que hemos mencionado extiende la potencialidad del daño en el tiempo (el peligro está allí latente) y, por el otro, cuando esa potencia dañina se actualiza, esto es, cuando una MAP o un REG es activado, ese acto transforma la forma en que se experimenta la vida cotidiana en el territorio, en particular para aquellos que han sido víctimas directas de esas armas: "emocionalmente $y$ psicológicamente la zozobra y la intranquilidad dejan un recuerdo para siempre" (Mujer, entrevista personal, San Francisco, 26 nov. 2016). Es en este sentido que Nogué (2014, p. 157) ha señalado que los lugares son esenciales para nuestra "estabilidad emocional". Si nuestro lugar en el mundo se altera de forma violenta, nuestra estabilidad emocional se ve también alterada.

¿Qué queda del sentido de territorio cuando los habitantes del mismo se ven obligados a experimentarlo con temor? ¿Qué queda 
Devenir inhóspito del hogar: transformaciones territoriales por la presencia de minas...

de ese sentido cuando el vínculo emocional con el propio lugar está atravesado por el miedo? Lo que en geografía humana se conoce como "construcción social del paisaje" (NOGUÉ, 2007), que en los términos aquí empleados corresponde al vertimiento de sentido sobre un territorio, se da a través de un largo proceso por medio del cual una comunidad percibe, moldea e interioriza el lugar en el que vive. Un territorio, en tanto hogar de una comunidad, está constituido entonces por lugares percibidos, moldeados e interiorizados como centros de significado social.

Lo que la guerra hace en un territorio, y en particular la práctica de instalar MAP en él, es destruir de forma violenta este significado social. Tal destrucción resulta traumática para los locales, en la medida en que a pesar de que ellos no participan ni son consultados sobre esa transformación (NOGUÉ, 2014), sí se ven obligados a convivir con ella o, para el caso del oriente antioqueño, a desplazarse forzosamente debido a ello. Un indicador de que el sentido de lugar se ha transformado, en este caso por la presencia de MAP, es el hecho de que la forma en que el territorio se percibe, y por tanto se interioriza, ha cambiado:

\section{9}

(...) los paisajes ya no son los mismos cuando uno deja de pasar por donde había que pasar a hacerle mantenimiento y tal cosa... se crece el monte. (Hombre adulto, entrevista personal, San Francisco, 16 jun. 2017)

De lo que hablamos es del rompimiento de la experiencia del territorio, o dicho con Bourdieu (2019, p. 321), el quiebre de "la causalidad de lo probable", de aquello

(...) que se adquiere mediante la confrontación repetida con un mundo social estructurado según cierta lógica, es decir, esta suerte de disposiciones a anticipar lo que sucederá y a esperar lo que sucederá (...) esta disposición a adelantarse, a anticipar lo probable. 
Devenir inhóspito del hogar: transformaciones territoriales por la presencia de minas...

No poder pasar por donde había que pasar significa, aquí, que la idea de transitar ciertos lugares empieza a dejar de estar asociada a la experiencia previa de un mundo estructurado a partir de probabilidades más o menos conocidas. Lo que sucede es que no puede confiarse más en la experiencia pasada del lugar.

Una de las formas -quizá la más radical- en que los habitantes del oriente antioqueño buscaron confrontar ese quiebre fue desplazándose forzosamente de sus hogares. El CNMH (2017) nota que la presencia de MAP no sólo es causa del desplazamiento forzado, sino que además añade peligro adicional al propio acto del desplazamiento (independiente de su casusa inmediata), ya que en situaciones en que las personas deben huir de forma apresurada (en un contexto de combates entre grupos armados, por ejemplo), éstas se ven obligadas a transitar por lugares que a priori pueden ser peligrosos por la sospecha de presencia de dichos artefactos.

Cuando las mujeres de Cocorná, participantes en los talleres de memoria, realizaron el ejercicio de cartografía social de reconstrucción de su territorio, plasmaron claramente esta relación. La Imagen 1 narra una experiencia colectiva: se trata de un mapa de afectación de MAP construido por ellas, en el cual se registra la continuidad entre la victimización por MAP y el desplazamiento forzado; la línea roja que comienza en un evento por minas en el año 2004 (abajo a la izquierda en la imagen) termina en un desplazamiento forzado en el cual tuvieron que caminar por espacio de dos horas los pobladores de la vereda que huyeron aquel día. La línea roja conecta así varias activaciones de MAP, separadas apenas por días, con ese acontecimiento final, en una causalidad que en el dibujo se presenta incluso de forma directa. 
Devenir inhóspito del hogar: transformaciones territoriales por la presencia de minas...

Imagen 1. Detalle cartografía social de las mujeres de Cocorná.

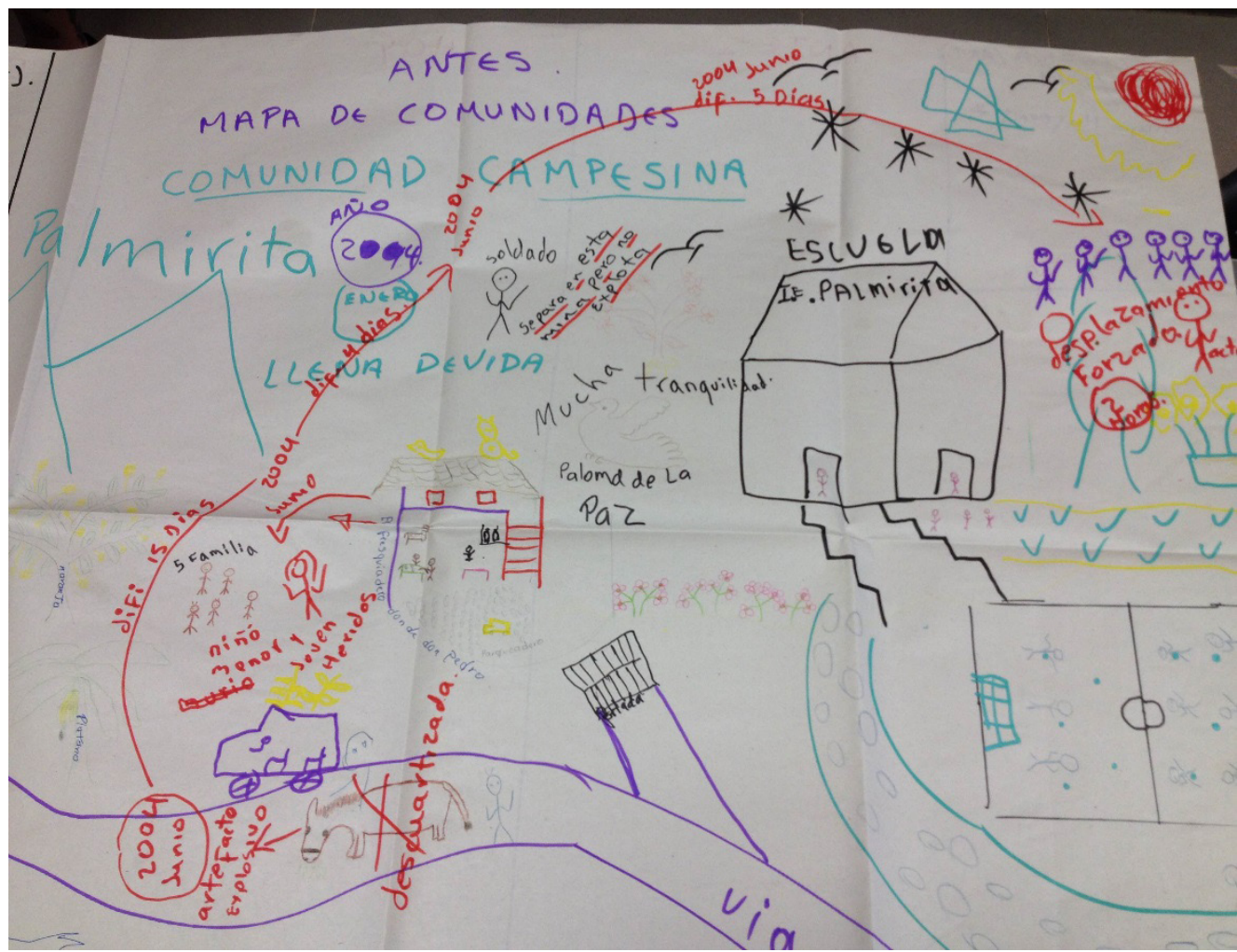

Fuente: Archivo personal de los autores.

Es entonces el desplazamiento forzado una acción bélica que aumenta el riesgo de ser víctimas de MAP en los territorios donde éstas ya están. Huyen para alejarse de un peligro, pero esa misma huida los obliga a atravesar por caminos que esconden otro peligro del que también huyen. En este punto se entrecruza el accionar de los grupos paramilitares de ultraderecha con el de los grupos guerrilleros. En Colombia, los grupos paramilitares han sido el principal agente responsable del desplazamiento forzado en el país (CNMH, 2013). En el oriente antioqueño, entonces, ha sido la guerrilla la responsable directa de la instalación de MAP y los paramilitares han sido perpetradores de acciones que han aumentado la vulnerabilidad de la población civil frente a estos artefactos. En el año 2000, por ejemplo, los paramilitares llegados desde el Magdalena Medio (una región colindante con el oriente antioqueño) generaron el desplazamiento forzado de todas las 
Devenir inhóspito del hogar: transformaciones territoriales por la presencia de minas...

veredas ubicadas a menos de 200 metros de la autopista MedellínBogotá:

[Los paramilitares] desocuparon por completo [la autopista]. A la gente la sacaron desde el alto de Palmitas, a la gente le pasaron unos volantes. Aparecieron por ahí diciendo que necesitaban este sector, desde Alto Bonito hasta Doradal, sólo porque necesitaban esto despejado. Eso decían los volantes... que tenían 24 horas para salirse. (Hombre adulto, taller de memoria, San Luis, 15 ago. 2015)

Esa zona específica, los alrededores de la autopista MedellínBogotá, tenía MAP instaladas por la guerrilla, siguiendo la señalada lógica de protección de la huida. Esas MAP tuvieron un efecto directo sobre los civiles precisamente cuando los pobladores tuvieron que despejar forzosamente las áreas aledañas a la autopista, como lo recordaba una mujer campesina en el desarrollo de una actividad de memoria donde hablábamos sobre las acciones de los grupos armados que arribaron al territorio:

(...) Eso nadie se dio cuenta cuando [los guerrilleros] las enterraron [las MAP]). Eso como que lo enterraron como en el 2000, 2001 o 2002 y la gente vino a caer en la mina cuando esto lo desocuparon [los paramilitares] por completo. (Mujer adulta, taller de memoria, San Luis, 15 ago. 2015)

En la trama de las narraciones de las víctimas se denota, así, el peligro asociado al movimiento sobre el territorio que era familiar. Sea en desarrollo de labores cotidianas o en la huida debido a las dinámicas de la guerra, el territorio se transforma en una trampa en la cual caen aquellos que hasta ayer lo recorrían en tanto lugar conocido. Las MAP se constituyeron así en el síntoma de lo que aquí llamamos el devenir siniestro o inhóspito del territorio, en el sentido dado al término por Freud (1968, p. 2484): “lo siniestro 
Devenir inhóspito del hogar: transformaciones territoriales por la presencia de minas...

sería aquella suerte de espanto que afecta las cosas familiares y conocidas desde tiempo atrás (...) lo siniestro sería siempre algo en que uno se encuentra, por así decirlo, desconcertado, perdido".

Como concepto, lo siniestro no pertenece al campo de los estudios sociales, y ni siquiera al psicoanálisis, sino que viene de los estudios estéticos y literarios (MITCHELL, 2019). Es en esa línea en la que, por ejemplo, Trías (1984) señala que lo siniestro constituye la condición y el límite de lo bello. En tanto que condición, no puede darse efecto estético sin que lo siniestro esté presente. En tanto que límite, la revelación de lo siniestro destruye el efecto estético. Algo parecido a esto decimos nosotros con respecto a lo territorial, y más específicamente, a la idea del hogar.

Lo siniestro: lo ominoso, lo inquietante, lo pavoroso. Freud (1968) mismo nos advierte respecto de la difícil traducción y especificación del significante. Es aquello que genera angustia. No puede ser desvelado. Es lo sospechoso. Fue López-Ballesteros, traductor de Sigmund Freud, quien decidió enmarcar esta fuente de angustia frente a lo desconocido en la noción de lo siniestro, aduciendo su vinculación con el latín sinister, que alude al lado izquierdo, y, por metonimia, a todo lo maligno, siguiendo en esto el análisis simbólico de Hertz (1990). De lo que hablamos es, entonces, de la inquietante extrañeza de lo familiar que hace que el territorio devenga inhóspito, es decir, un lugar que va dejando de ofrecer hospitalidad, un lugar que va mutando del seno protector a la hostilidad.

En esa mutación que parece permanecer, en el devenir de algo que aún no ha dejado de ser lo que era, pero ya es también otra cosa, donde reside la transformación siniestra que producen las MAP en un territorio. Das Unheimliche, lo siniestro, es aquí entonces la sensación producida por el devenir inhóspito de lo familiar. Esto concuerda con lo señalado por Trías (1984, p. 32) cuando dice que "sentirse unheimlich es sentirse incómodo". La incomodidad viene del hecho de que algo se revela extraño a pesar de ser -o precisamente por ello- "lo más propiamente familiar" (TRÍAS, 1984, p. 33), algo que hasta ayer era completamente reconocible. 
Devenir inhóspito del hogar: transformaciones territoriales por la presencia de minas...

Mediante la instalación de MAP, los grupos armados transformaron en inhóspito, y por tanto, hasta cierto punto, transformaron en ajeno el territorio que las poblaciones sentían como propio. Y no sólo ajeno en tanto desconocido, sino en tanto "espantoso" en la medida en que el elemento que añadía la extrañeza producía temor debido al peligro que representaba. Al hablar de lo siniestro-inhóspito asociamos, así, lo familiar (el territorio, en su apariencia superficial, sigue incluso pareciendo igual) con el peligro potencial que yace escondido en él en los terrenos donde se han instalado aquellos artefactos. Es por esto que "llevado más lejos, [lo siniestro] designa también algo más que lo oculto, se refiere a lo ocultado, lo escondido" (ERRÁZURIZ, 2020).

En esta dirección, una mujer que vivía en zona rural de San Francisco y que tuvo que abandonar su casa debido a las activaciones de MAP que se habían producido y a la sospecha de la presencia de más de esos artefactos en la vereda donde vivía, decía lo siguiente respecto de su antigua casa: "ya la gente casi no sube por allá [a la zona montañosa] como 'que no, que qué miedo ir por allá', que hay minas y no pasan" (Mujer joven, entrevista personal, San Francisco, 25 nov. 2016). El lugar familiar, conocido, empieza a ser identificado como espacio amenazante que, literalmente, puede estallar en cualquier momento. El efecto que tienen las MAP sobre el territorio constituye entonces el núcleo de una apropiación paradójica mediada por lo siniestro: se trata de una apropiación-rechazo, en la que los habitantes de un territorio lo contemplan como algo que les pertenece, los constituye, pero al que, simultáneamente, temen al no (re)conocerlo ya plenamente.

La paradoja de este devenir inhóspito del territorio se refleja en las decisiones vitales que deben tomar los pobladores locales, pues la extrañeza del territorio "propio" los pone frente a una perspectiva que niega el sentido de vivir en el campo: la del campesino que, por miedo a activar una MAP, no cultiva su tierra. Una de las participantes en los talleres de memoria resume de manera precisa esta incertidumbre al señalar, frente a la pregunta de la relación actual de las comunidades con su territorio, que 
Devenir inhóspito del hogar: transformaciones territoriales por la presencia de minas... Gabriel Ruiz Romero • Daniel Castaño Zapata

"después de la violencia todavía hay gente que quiere trabajar el campo y sembrar en los rastrojos plátano, maíz y frijol, pero a muchos les da miedo volver porque ya perdieron su vida en el campo" (Mujer adulta, taller de memoria, San Francisco, 15 sep. 2015).

Así, como consecuencia de la presencia de MAP en las zonas rurales indagadas, muchas personas terminaron por dejar de hacer las actividades que le daban sentido al territorio. Las dinámicas bélicas, entre las que aquí hemos destacado el empleo de MAP, produjeron que algunas veredas quedaran prácticamente desocupadas. Muchas de ellas permanecieron así incluso después de que los hombres armados dejaran de hacer presencia y ejercer presión en esos lugares, pues, aunque esos ejércitos se fueran, las MAP quedaron allí como una señal de que el poder de destrucción de la guerra aún continuaba. En San Francisco es esto lo que no había posibilitado que los pobladores rurales volvieran con tranquilidad de nuevo a sus hogares: "Ia mayoría [de veredas] están solas porque en este momento todavía hay presencia de minas... la lejanía, ya todo se acabó, ya hay mero monte [mucha maleza]" (Mujer adulta, taller de memoria, San Francisco, 15 sep. 2015).

La presencia de MAP produce lejanía, imposibilidad de acercamiento, de familiarización cotidiana con el lugar. Crea un límite que hace que el lugar (antes cercano, incorporado), tenga que habitarse desde lejos. La imagen del monte tomándose de nuevo los lugares es la de las personas alejadas de esos mismos lugares. Dice Relph (1976, p. 12) que un espacio cualquiera se transforma en un "espacio existencial" en la medida en que él es habitado a partir de nuestras concretas experiencias, en la medida en que es creado y re-creado a través de las actividades humanas. Así, al devenir inhóspito del territorio lo podemos definir como el acto de destrucción de la existencia localizada concreta.

De lo que hablamos es de una experiencia desde adentro de des-territorialidad: la de sentirse un forastero dentro del propio territorio. Los habitantes están adentro, en la región, en lo que han aprendido a llamar su hogar, pero es un adentro transformado, pues no sólo en ocasiones están literalmente confinados allí (como 
Devenir inhóspito del hogar: transformaciones territoriales por la presencia de minas... Gabriel Ruiz Romero • Daniel Castaño Zapata

niños en escuelas rurales que no pueden salir a los potreros porque allí hay MAP), sino que el sentido del lugar ha cambiado por la incertidumbre producida debido a la presencia de artefactos explosivos potencialmente en cualquier lugar. La familiaridad del territorio se hace así extraña y ello es lo que introduce lo siniestro: no se instalan solo MAP en un espacio geográfico, sino que se instala el miedo como definitorio del territorio, lo cual, en último término, anula el propio sentido del lugar.

Reescribir el sentido, verter una nueva carga semántica territorial para indicarle a los pobladores (a los que seguían resistiendo desde su propio territorio, los que aún confinados trataban de no salir huyendo hasta que no hubiese más opción, pero también a los que buscando proteger sus vidas y su integridad habían salido forzosamente desplazados), para indicarle a todos ellos, entonces, que esos paisajes ya no eran los mismos, pues estar adentro (del territorio) era también una forma de estar afuera de él, en el sentido de que la lógica bélica buscaba que ese territorio no fuese más asumido como un hogar. Es la producción de extrañeza sobre lo antes familiar lo que ubicamos en el centro de lo aquí analizado.

\section{Resistencia: leer las marcas en el territorio}

El paisaje minado fue creado, en el contexto de la guerra colombiana, con el propósito de crear una nueva significación siniestra o inhóspita del territorio. En algunos casos, esa nueva carga semántica se transmitía a los habitantes locales en la medida en que se veían obligados a transitar por caminos donde temían pudiera esconderse el nuevo peligro. Una mujer campesina de San Luis, quien abandonó su vereda y se fue a vivir al área urbana debido a la presencia de MAP, recuerda que en los últimos días cuando vivía en el campo sentía "un cosquilleo" cada vez que caminaba por los parajes rurales de su vereda. Esa misma mujer afirma que "ya no sería capaz de volver a vivir en el campo asi" (Mujer, entrevista personal, San Luis, 16 jun. 2017). 
Devenir inhóspito del hogar: transformaciones territoriales por la presencia de minas...

¿Qué significa ese así al final de su sentencia? No dice ella que no volvería a vivir en el campo de ninguna manera; lo que afirma es que en la forma en que lo estaba haciendo no sería capaz de hacerlo. Para hacerlo entonces, tendría que dejar de sentir esa alarma corporal (esa extrañeza) que le indica que camina sobre el peligro y poder así recorrer los caminos despreocupadamente, que es la única forma admisible de caminar.

Es justo para no llegar a sentir ese cosquilleo después que las comunidades buscaban, en primer lugar, oponerse a la propia siembra de los artefactos en sus tierras. Pero de lo que hablamos es de territorios donde la guerrilla llegó a constituir autoridad, en el sentido de ejercer ejercicios de soberanía. La oposición, por tanto, podía ejerce dentro de límites muy estrechos. En los talleres, las comunidades locales recordaron episodios aislados en los cuales lograron que un gripo no instalara MAP en el territorio, pero ello solo era temporal. Volvían y las instalaban, aduciendo estar así protegiendo el propio territorio del enemigo, aunque así -en la práctica- terminaran atacando a la propia población: "sembraban minas para el ejército, pero no le avisaban a la comunidad" (Mujer, taller de memoria, Cocorná, 10 sep. 2015).

No siempre entonces era posible impedir que las minas fuesen instaladas y no siempre la ubicación de esas minas era conocida. Es por ello que el devenir siniestro es incertidumbre insertada en el territorio. Incluso cuando los propios actores armados informan a las comunidades locales sobre la instalación de MAP, lo hacen en tanto forma de control social y sin revelar exactamente dónde lo han hecho. Y si hacen esto último, se trata de un conocimiento envenenado (DAS, 2002) puesto que, por una parte, no es posible compartirlo con otros (sobre ello pesa una amenaza) y tal conocimiento puede hacer sospechosa, a posteriori, a aquella persona que lo recibió.

Frente al devenir inhóspito del territorio, la comunidad debía entonces re-leer el paisaje para poder trazar en él nuevas fronteras que los protegiera de esos riesgos ahora ocultos en él. Esto requería un alejamiento: "dejar de ir a muchos trabajaderos, no volviendo a 
Devenir inhóspito del hogar: transformaciones territoriales por la presencia de minas... Gabriel Ruiz Romero • Daniel Castaño Zapata

partes donde uno veía que la guerrilla, los paramilitares y el ejército se mantenían, por las minas" (Mujer, taller de memoria, Cocorná, 10 sep. 2015). Los lugares tienen un gran poder de resonancia en la imaginación (BESSE, 2006) y por ello unos espacios concretos empezaron a resonar en el imaginario colectivo como espacios a evitar, como fronteras que no se podían cruzar.

En los ejercicios de cartografía social efectuados en los tres municipios donde se centró este trabajo de investigación, se le pidió a los participantes que, después de construido el mapa de su territorio, señalaran en él los lugares donde habían ocurrido ataques por MAP (además de otras afectaciones por el conflicto armado). Lo que se veía al final era la superposición de los lugares donde concurría la vida diaria de la comunidad y los lugares donde las MAP fueron instaladas. En el ejercicio de cartografía social realizado por las mujeres en Cocorná (Imagen 1), por ejemplo, es la escuela la que aparece como central en el mapa y alrededor de ella está trazada la victimización producida por el conflicto armado, en particular la ocasionada por las MAP. Los centros de producción de significado social (como la escuela) amenazados así por la resignificación violenta del territorio.

No se ha tratado entonces de una forma de victimización pasiva. Antes de que muchos tomaran la decisión de huir (la que en un momento dado resultó inevitable frente al poder avasallador de esos hombres en armas y la incapacidad del Estado para protegerlos), las personas buscaron desarrollar estrategias de recogimiento que les permitiera permanecer en su territorio: "ya la gente comenzó a buscar círculos muy cercanos a la vereda, a las casas, y ya a trabajar en las partes más cerquitas" (Mujer, taller de memoria, San Francisco, 15 sep. 2015).

Buscar círculos cercanos, estar cerca a la casa, circunscribir de nuevo el lugar. Se buscaba así defender la idea del espacio como lugar de la inserción del hombre en el mundo, como lugar para "combatir por la vida" (DARDEL, 2013, p. 44). Hacerlo requiere justamente ocupar nuevos espacios u ocupar los espacios habituales, pero aprendiéndolos a leer en su gramática actual para así debilitar el 
Devenir inhóspito del hogar: transformaciones territoriales por la presencia de minas... Gabriel Ruiz Romero • Daniel Castaño Zapata

carácter inhóspito que les ha sido impuesto. Se trata de una creación de "geografías de resistencia" (PILE y KEITH, 1997) en tanto intento común de re-organizar la forma de habitar un territorio para buscar seguir conservándolo en tanto hogar, en tanto lugar que aún puede ofrecer hospitalidad.

Es por lo anterior que la labor de desminado de los territorios constituye una acción de paz necesaria si se quiere confrontar los efectos sociales de la violencia. Volver de nuevo familiar lo propio es lo que puede lograr el trabajo de desminado. En la actualidad, es a través del llamado desminado humanitario como se busca extraer lo siniestro del territorio. Se trata de un procedimiento mediante el cual entidades certificadas hacen un análisis de la presencia de MAP en un territorio concreto, revisando las áreas locales donde hay sospecha de presencia de esas armas y proceden así a su extracción. Los municipios en los cuales tiene lugar el proceso reciben al final del mismo una certificación de "municipio libre de sospecha de minas antipersonal".

Hasta el año 2019, San Francisco y Cocorná ya habían recibido esta certificación. San Luis está "en intervención" y se espera que pronto también sea declarado libre de sospecha de minas (AICMA, 2020b). Libre de sospecha no significa que pueda garantizarse que no hay más MAP en el territorio: sólo que allí donde se sospechaba que había ya ha sido revisado y no hay. Nuevas MAP no detectadas en el proceso de desminado, sin embargo, pueden aparecer en un futuro. Pero aunque la incertidumbre permanezca aún por tiempo indefinido, el desminado es el requisito sine qua non para poder empezar a confrontar el proceso de devenir siniestro del territorio que aquí hemos analizado.

\section{Conclusión}

La presencia de MAP en un territorio transforma radicalmente las dinámicas sociales que se desarrollan en su interior, pues introduce un elemento de incertidumbre allí donde transcurre 
Devenir inhóspito del hogar: transformaciones territoriales por la presencia de minas... Gabriel Ruiz Romero • Daniel Castaño Zapata

la vida cotidiana, modificando así el sentido social de ese territorio. Esta incertidumbre no es solo la que se construye por la falta de previsibilidad de la vida diaria, sino que se trata de una incertidumbre radical, cuyo fundamento es el riesgo a perder una parte del cuerpo o lavida misma. Al transformar lo acostumbrado en hostil, al tiempo que se mantiene cierta apariencia de familiaridad, el uso de MAP torna siniestro o inhóspito el territorio lo cual hace que las apropiaciones que sobre él desarrollan sus habitantes son experiencias paradójicas de apropiación y rechazo simultáneos.

Las distintas afectaciones que causan las MAP en los individuos no son independientes y por ello no se restringen a un daño físico, sino que generan toda una reacción en cadena de situaciones que afectan múltiples dimensiones de la vida de una persona. Es por esto que estudiar las afectaciones producidas por estos artefactos permite entender que la corporalidad trasciende los límites físicos del cuerpo; entender que la corporalidad es también un dispositivo de conocimiento del mundo y que ese dispositivo se ve afectado cuando el entorno que habita se ha transformado debido a la presencia o la sospecha de presencia de MAP y REG.

La instalación de MAP en los territorios rurales constituye, así, uno de los repertorios de las lógicas bélicas que nefastamente se han desplegado en el campo colombiano en desarrollo del conflicto armado, transformando las lógicas cotidianas debido a la producción de un entorno caracterizado por la incertidumbre, esto es, tornándolo siniestro, inhóspito. Como lo ha señalado Pécaut (2013, p. 160), la incertidumbre es una característica central de la violencia incorporándose en el día de a día de sus habitantes:

A partir del momento en que el conflicto se extiende a una gran parte del país, la incertidumbre se convierte en el horizonte que está presente en todos los instantes. Los espacios conformados alrededor del dominio de los actores armados se vuelven móviles y fluidas las fronteras que los separan. 
Devenir inhóspito del hogar: transformaciones territoriales por la presencia de minas... Gabriel Ruiz Romero • Daniel Castaño Zapata

En este sentido, la instalación de MAP altera el sentido que un territorio tiene para una comunidad porque logra -literal y simbólicamente- transformar el entorno en el cual se desenvuelve la vida individual y social. Su poder devastador es profundo pues las MAP marcan los territorios de manera diacrónica, porque incluso mucho más allá del eventual cese de hostilidades que se dé sobre ese territorio aquellas pueden permanecer potencialmente activas muchos años después del fin de la guerra.

\section{Referencias}

AGENCIA DE ACCIÓN INTEGRAL CONTRA MINAS ANTIPERSONAL - AICMA.

\section{Estadísticas de Asistencia Integral a las Víctimas de MAP y}

MUSE. 2020a. Disponible en: http://www.accioncontraminas.gov. co/Estadisticas/Paginas/Estadisticas-de-Victimas.aspx. Acceso en: 8 nov. 2020.

\section{1}

AGENCIA DE ACCIÓN INTEGRAL CONTRA MINAS ANTIPERSONAL - AICMA.

Resultados de las operaciones para liberación del territorio. 2020b. Disponible en: http://www.accioncontraminas.gov.co/ Estadisticas/operaciones-dh. Acceso en: 8 nov. 2020.

AGUILERA, Mario. El ELN: entre las armas y la política. In: WILLS, María Ema; SÁNCHEZ, Gonzalo (ed.). Nuestra guerra sin nombre: transformaciones del conflicto en Colombia. Bogotá: Norma, 2006. p. 209-266.

BESSE, Jean Marc. Las cinco puertas del paisaje. In: MARCHAN, Simón; MADERUELO, Javier (coord.). Paisaje y pensamiento. Madrid: Abada, 2006. p. 145-172.

BOURDIEU, Pierre. Curso de sociología general. Conceptos fundamentales. México, DF: Siglo XXI, 2019. v. 1. 
Devenir inhóspito del hogar: transformaciones territoriales por la presencia de minas... Gabriel Ruiz Romero • Daniel Castaño Zapata

CENTRO NACIONAL CONTRA ARTEFACTOS EXPLOSIVOS Y MINAS CENAM. Cartilla Llamar las Cosas por su Nombre. empleo correcto de términos referente a artefactos explosivos AE-EO. Disponible en: http://www.acore.org.co/wp-content/uploads/2017/10/ CARTILLA-EJERCITO-Desminado.pdf. Acceso en: 31 ene. 2020.

CENTRO NACIONAL DE MEMORIA HISTÓRICA - CNMH. ¡Basta ya! Colombia. Memorias de guerra y dignidad. Bogotá: Imprenta Nacional, 2013.

CENTRO NACIONAL DE MEMORIA HISTÓRICA - CNMH. La guerra escondida. Minas antipersonal y remanentes explosivos en Colombia. Bogotá: CNMH, 2017.

DARDEL, Eric. El hombre y la tierra. Naturaleza de la realidad geográfica. Madrid: Biblioteca Nueva, 2013.

DAS, Veena. The act of witnessing: violence, poisonous knowledge and subjectivity. In: DAS, Veena et al. (eds.). Violence and subjectivity. Berkeley, CA: University of California Press, 2002. p. 205-225.

ERRÁZURIZ, Pilar. El rostro siniestro de lo familiar: memoria y olvido. Disponible en: https://web.uchile.cl/publicaciones/cyber/19/errazuriz.html. Acceso en: 9 ene. 2020.

FREUD, Sigmund. Obras completas de Sigmund Freud. Madrid: Biblioteca Nueva, 1968. v. 7.

FUNDACIÓN SEGURIDAD \& DEMOCRACIA. Informe especial conflicto y minas antipersonal en Colombia. 2006. Disponible en: http://www.acnur.org/t3/uploads/media/1726.pdf?view=1. Acceso en: 20 ene. 2020.

GENEVA INTERNATIONAL CENTRE FOR HUMANITARIAN DEMINING - GICHD. A guide to mine action. Geneva: GICHD, 2014.

GÓMEZ, Santiago; HINESTROZA, Paula; MUÑETÓN, Guberney. Procesos poblacionales en Antioquia, Colombia, a partir de relaciones de parentesco intermunicipales. Papeles de Población, v. 14, n. 57, p. 257-274, 2008. 
Devenir inhóspito del hogar: transformaciones territoriales por la presencia de minas... Gabriel Ruiz Romero • Daniel Castaño Zapata

GRUPO DE MEMORIA HISTÓRICA - GMH. La Masacre del Salado: esa guerra no era nuestra. Bogotá: Taurus-Fundación Semana, 2009.

HERTZ, Robert. La muerte y la mano derecha. Madrid: Alianza Universidad, 1990.

MARCUS, George. Ethnography in/of the world system: the emergence of multi-sited ethnography. Annual Review of Anthropology, v. 24, p. 95-117, 1995.

MITCHELL, William. La ciencia de la imagen, iconología, estética visual de los medios. Madrid: Akal, 2019.

NOGUÉ, Joan (ed.). La construcción social del paisaje. Madrid: Biblioteca Nueva, 2007.

NOGUÉ, Joan. Sentido del lugar, paisaje y conflicto.

Geopolítica(s), v. 5, n. 2, p. 155-163, 2014.

OBSERVATORIO DE LA CONSEJERÍA PRESIDENCIA PARA LOS DERECHOS HUMANOS. Atlas del impacto regional del conflicto armado en Colombia. Dinámicas locales y regionales en el periodo 1990-2013. Bogotá: Imprenta Nacional de Colombia, 2015. v. 1.

OBSERVATORIO DEL PROGRAMA PRESIDENCIAL DE DERECHOS HUMANOS Y DERECHO INTERNACIONAL HUMANITARIO.

Panorama actual del Oriente Antioqueño. Bogotá:

Vicepresidencia de la República, 2003. (Serie Geográfica No. 22).

OBSERVATORIO DE MINAS ANTIPERSONAL; DEFENSORÍA DEL PUEBLO; UNICEF. Manual del facilitador comunitario. Acción humanitaria contra minas. Bogotá: Gente Nueva, 2005.

PÉCAUT, Daniel. La experiencia de la violencia: los desafíos del relato y la memoria. Medellín: La Carreta, 2013.

PEÑATE, Andrés. El sendero estratégico del ELN: del idealismo guevarista al clientelismo armado. In: LLORENTE, María Victoria; MALCOLM, Deas (comp.). Reconocer la guerra para construir la paz. Bogotá: Universidad de Los Andes, 1999. p. 53-98. 
Devenir inhóspito del hogar: transformaciones territoriales por la presencia de minas... Gabriel Ruiz Romero • Daniel Castaño Zapata

PILE, Steve; KEITH, Michale (eds.). Geographies of resistance. London: Routledge, 1997.

PROGRAMA DE LAS NACIONES UNIDAS PARA EL DESARROLLO PNUD. Oriente Antioqueño. Análisis de la conflictividad. Bogotá: PNUD, 2010.

RELPH, Edward. Place and placelessness. London: Pion, 1976.

SANDOVAL, Jairo et al. El conflicto armado en las regiones. Bogotá: Ed. Universidad del Rosario, 2017.

SCHELER, Max. El puesto del hombre en el cosmos. Madrid: Escolar y Mayo, 2017.

SCHELLING, Friedrich. Filosofía del arte. Madrid: Tecnos, 2006.

SEGUINOT, José. The urban ecology of San Juan: a social geographic interpretation. Anales de Geografía de la Universidad Complutense, v. 16, p. 161-184, 1996.

TRÍAS, Eugenio. Lo bello y lo siniestro. Barcelona: Seix Barral, 1984.

URIBE, María Teresa (coord.). Desplazamiento forzado en Antioquia. 1985-1998. Medellín: Universidad de Antioquia, 2001. VALENCIA, Paula; RUIZ, Gabriel. Expresiones de violencia basada en género en los ataques por minas antipersonal. Caso de estudio en Colombia. Revista de Dialectología y Tradiciones Populares, v. 71, n. 2, p. 535-557, 2016.

VERDAD ABIERTA. Las FARC cosecharon odios en el oriente antioqueño. 2014. Disponible en: https://verdadabierta.com/ las-farc-cosecharon-odios-en-el-oriente-antioqueno/. Acceso en: 22 ene. 2020.

WERNER, Oswald; SHOEPFLE, Mark. Cuestiones epistemológicas. In: VELASCO, Honorio (comp.). Lecturas de antropología social y cultural. La cultura y las culturas. Madrid: UNED, 1993. p. 113-181. 